\title{
PRICING OF THE TOURISM PRODUCT: A TOOL FOR ENTREPRENEURS TO ADAPT TO A FLEXIBLE MARKET
}

\author{
Anuța Buiga, Roxana Stegerean, Alexandru Chiş, Dorina Lazăr
}

\section{Introduction}

During the last decades, the tourism industry from Central and Eastern European countries has gained an increasing importance. Because of the diversity of businesses and activities inside this sector, the tourism can be considered an effective engine for emerging sectors and for economy. Furthermore, due to its diverse, beautiful nature and valuable historical and cultural inheritance we consider that the tourism sector has growth potential, high efficiency and thus, opportunities for significant contributions both to national GDP and added value. Focusing on Romania, the favourable geographical position and landscape structure support the practice of various forms of mass and alternative tourism. According to the WTTC methodology (World Travel \& Tourism Council, 2014), the total contribution of travel and tourism to GDP has been of $5.1 \%$ in 2013 , and is predicted a growth potential of $3.8 \%$ per annum over the next ten years, while for European Union the total contribution of travel and tourism to GDP is forecasted to rise by $2.6 \%$ per annum.

Within the context of tourism development, more small and medium accommodation establishments have been lately developed in the country than big size ones. According to the National Institute of Statistics, the Romanian tourism sector included 6,009 tourist accommodation establishments in 2013. A percentage of about $90 \%$ belongs to the entirely private system, while more than $97 \%$ are small and medium establishments with less than 50 employees. The guest house category, including both urban and rural type, records the most significant increase.

The development trend of small and medium enterprises emphasizes the increasing importance of entrepreneurship within the tourism sector. Based on Schumpeter's early theory of economic development, more recent approaches view entrepreneurship as a promoter of economic development and named innovation the key element for sustaining it (Bull, Thomas, \& Willard, 1995). When referring to innovation we don't consider only the component of developing new products and services, but also the stage of developing new strategies in the tourism establishments (Hamel, 2007). In order to reach the goals both approaches need entrepreneurial initiatives and ask for a high level of involvement of managers.

Due to the increase in the number of establishments being developed the competition has begun to be strengthened. Meanwhile, the market needs are more and more diverse which leads to new and various challenges for an effective and efficient management of the accommodation establishments in order to adapt them to a flexible and dynamic market. The effectiveness and efficiency of the accommodation establishments are influenced by continuous changes in consumer preferences. Thus, in order to be successful a tourism entrepreneur has to establish goals within the accommodation unit which could drive high levels of customer satisfaction. Some of the important issues are externallyoriented and refer to tourist profile identification - life style, actual and potential needs not included in the current offer, motivation for choosing different destinations. Meanwhile, the entrepreneur has to be internally-oriented and to focus on innovation, operations and other internal elements which ultimately determine the same increase in customer satisfaction.

Tourists get satisfaction from each of the components of a particular touristic product (Rigall-I-Torrent \& Fluvia, 2011). Thus, hotel customers derive utility from all the available facilities, surroundings or other elements which can be considered for improving the delivered 
service - size of the room, quality of the goods and equipment, quality of food, communication with staff, other specific services included and made available by the accommodation establishment itself - healthcare, wellness, transportation. Meanwhile, it is very important to focus on the external availabilities which do not belong to the accommodation establishment, but to other organizations - private or state owned companies, local municipality. These attributes are referred as public characteristics (Rigall-I-Torrent \& Fluvia, 2011), but they clearly state that ultimately, the consumer's choices depend on the specific combination of public and private attributes which give rise to the final product.

The link between entrepreneurs and market needs is sustained through marketing policies and strategies, respectively through the marketing mix components- product, price, placement and promotion. This paper focuses on the price as long as this is the element of the marketing mix which generates revenues, being at the same time more flexible than the other components (Kotler \& Keller, 2011). Therefore, the price of touristic products has a high impact on the revenues and profit.

The management of tourism establishments should have competences and abilities to design a pricing policy which enables higher level of performance, determined by a price competitive advantage. Our study conducts an empirical analysis on the private and public attributes and their influence on the room rate. Price represents an instrument for adapting the strategy of entrepreneurs not only for the business start-up, but also for the entire life of the tourism entity. It is important for entrepreneurs to understand the role of pricing and its flexibility in tourism because of the specificities mentioned above. As point out in Kotler and Keller (2011), the price formation is more challenging in the current changing economic and technological environment.

The touristic product is complex and consists of goods and services gathered and offered to the client. Therefore, the price of a touristic product is defined through a group of observable attributes. The final satisfaction obtained by a tourist depends on the combination of these goods and private or public services; they are delivered by different entities, either public or private (Salo, Garriga, Rigall-I-Torrent, Vila, \& Fluvià, 2014).
The hedonic pricing analysis is a valuable instrument for our endeavour as long as it allows to identify the set of observable attributes defining the product and ultimately, setting the price. Even more, the hedonic model allows the quantification of the marginal contribution for each attribute in the overall price, as it results from the balance between supply and demand. The interaction supply-demand determines the marginal implicit price of attributes, and the willingness of the customer to pay for it. As mentioned in Chen and Rothschild (2010), managers from accommodation and hospitality industry can use the information provided by hedonic model to price the products and develop marketing strategies.

This paper highlights the hedonic pricing model as a useful instrument for managers and entrepreneurs, when they establish the pricing policy for their touristic products. We conducted the empirical analysis on the significant factors explaining the variation in the prices, for the Romanian accommodation establishments market. The purpose of the research is to identify and quantify the marginal contribution of each attribute to price formation. The findings are helpful to sustain the overall strategy but also some particular ones, referring to promoting or developing some services based on the marginal contribution of the attributes. The results are valuable for all categories of accommodation, whether start-ups or wellestablished businesses.

Our empirical research focuses on the marginal contributions of private and public attributes of accommodation establishments from Romania, to the room rates. The accommodation units in the sample are mostly oriented towards leisure tourism and are located in the rural areas of the country. The data related to room rates and attributes were collected from a Romanian tourism website. The attributes considered, as explanatory variables, in hedonic pricing models differ from paper to paper, according to the main objective of the research and availability of data. Taking account of the standardized factors used in previous papers and of the data available on the website, we consider, as important in determining the room rate, two groups of factors:

a) attributes specific to the accommodation unit: number of rooms in the accommodation establishment, type of establishment (guest 
house, villa and house, chalet, hotel), stars rating (4 stars, 3 stars, 2 stars), and dummy variables for providing breakfast, pets allowed, bicycle/ATV rent facility ( 1 indicates presence and 0 indicates absence);

b) attributes describing the location: nearby tourist attractions, close to the city, close to thermal baths, near lake, isolated place. These location characteristics are included in the hedonic models as dummy variables (1 indicates presence).

The impact of these factors on room rates is measured for the whole sample of accommodation units, for the sub-sample of units providing breakfast, and for the subsample of units not providing breakfast.

Section 1 from the paper describes the pricing hedonic model for differentiated products and reviews its applications in tourism sector. In Section 2 we describe the Romanian tourism products attribute and data set within the context of hedonic model. Section 3 conducts an empirical hedonic analysis of room rates, for a large sample of establishment units from Romania; the marginal utility is estimated for each attribute embedded in the price. At the end of the paper, based on the results from the empirical analysis, we highlight the conclusions and guidelines for managers, entrepreneurs or public organizations.

\section{Hedonic Pricing Analysis in Tourism}

The price of the room (room rate) is one of the most important criterion for a tourist when choosing among various accommodation facilities. The price setting decision for a tourism product is driven by a number of internal and external factors to the firm, such as the following: the objectives of the firm (e.g. a target market share, profit maximization), customer satisfaction, the degree of market competition, the firm's position on the market, capacity constraints, classification and grading systems, taxation, perishable nature of tourism products, the seasonality of tourism demand (Dwyer, Forsyth, \& Dwyer, 2010).

Previous studies about pricing in tourism, as Collins and Parsa (2006), Cassidy and Guilding (2007), Abrate, Fraquelli and Viglia (2012), Zhang, Zhang, Lu, Cheng and Zhang (2011), Papatheodorou, Lei, and Apostolakis (2012), among others, debate the fundamentals of pricing, pricing strategies and the pricing setting tools. Some authors, as Zhang et al. (2011) summarize and classify the hotel pricing empirical approaches into three categories, in terms of the methods used, namely consumer behavior, conjoint analysis, and hedonic analysis. The first two methods facilitate a direct investigation of the consumer's willingness to pay an implicit price for each attribute embedded in a tourism product; such an approach requires data collected through a consumer survey. As Zhang et al. (2011) point out, due to the actual and potential customer-oriented approach, the consumer behavior and conjoint analysis are more sensitive to be used by managers, and less objective than the hedonic analysis.

Focusing on the Romanian accommodation establishments market, this paper develops a hedonic pricing analysis, in order to estimate the implicit marginal prices associated to each attribute of tourism product. The theory of hedonic pricing has been developed by Rosen (1974), in the context of pricing differentiated products and services in a competitive market, under the hypothesis that "goods are valued for their utility-bearing attributes or characteristics". A tourism product is defined by a set of observable intrinsic characteristics. The overall price of the product is determined by the set of implicit prices of attributes, as these attributes are valued by the interaction of supply and demand.

In order to estimate the implicit prices of attributes, the first-stage of the econometric procedure proposed by Rosen considers a regression model in which the price of the product is considered as the dependent variable and the attributes are explanatory variables. This framework can estimate the marginal utility of the product attributes, and quantifies the willingness to pay for each attribute. The product price is regressed on their utility-bearing characteristics. The theoretical foundations of the hedonic model give little guidance in choosing a priori an appropriate functional form. Rosen (1974) mentions there are no reasons for hedonic function to be linear. As mentioned by Ekeland, Heckman and Nesheim (2004), the hedonic model is intrinsically nonlinear. In empirical research the most common used hedonic functional form is the log-linear model:

$$
\text { In } P=\beta_{0}+\beta_{1} X_{1}+\beta_{2} X_{2}+\ldots+\beta_{k} X_{k}+\varepsilon \text { (1) }
$$

respectively the log-log, the linear, and the flexible Box-Cox transformation. 
The econometric methodology should be selected according to theoretical guidelines and to statistical properties of the data. Our dependent variable, the price of the room, takes positive values. Moreover, as some empirical works suggest, usually the price has a positive skewed distribution. Due to the skewed distribution of hotel prices, in Hung, Shang and Wang (2010) is applied the quantile regression to study the determinants of hotel prices. The empirical papers from tourism research usually recognize this feature, considering the logarithm of price as dependent variable, and then, the classical linear regression methodology being applied. The log-transformation is applied to improve normality, linearity, and to stabilize the variance.

Within the context of positively skewed price distribution, we highlight the generalized linear models (GLM) framework, for estimating the hedonic model. These models are adequate to a large range of probability distributions for response variable, namely the exponential family distributions, that include the normal, Gamma, inverse Gaussian, exponential distributions, but also discrete distributions, among others. The Gamma and inverse Gaussian distributions are known to be appropriate for a positive variable, right-skewed. In a GLM framework, a link function $\mathrm{g}$ links the conditional mean of prices $E(P \mid X)=\bar{P}$ to the linear predictor:

$$
g(\bar{P})=\beta_{0}+\beta_{1} X_{1}+\beta_{2} X_{2}+\ldots+\beta_{k} X_{k}
$$

where $X=\left(X_{1}, X_{2}, \ldots X_{k}\right)$ is the set of touristic product characteristics. The generalized linear models are fitted to data using the method of maximum likelihood. The estimates for regression coefficients, and the asymptotic standard errors of coefficients are provided (McCullagh \& Searle, 2001).

Several papers have applied the hedonic pricing model in tourism and hospitality research, the most part being related to hotel industry, and to private characteristics of accommodation units. The paper Papatheodorou et al. (2012) summarize the evolution, advantages/ limitations, and applications of the hedonic price analysis in tourism.

Our approach is in line with the recent papers Chen and Rothschild (2010), Rigall-ITorrent and Fluvià (2011), Salo et al. (2014), among others. Chen and Rothschild (2010) studied the impact on the hotel room rates of common characteristics, as room size, location, the availability of some amenities like internet access, conference facilities, swimming pool, free parking, or room service. Data, related to the hotels from Taipei, has been collected from the website of a major travel agent.

Based on a hedonic analysis, Chen and Rothschild (2010) highlight several valuable implications for the managers and policymakers in tourism. The hedonic pricing model is applied to estimate the relative contribution to the room prices of private attributes (e.g. number of rooms, star rating, located near the beach, room services, availability of garden, car park, swimming pool, sport facilities), and public attributes (e.g. variables specific for jurisdiction as police officers, population, cultural facilities, sport facilities, restaurants, hotel rooms, coves). The prices and private attributes were collected from the tour operators' brochures, for a sample of hotels from Spain.

The paper of Salo et al. (2014) focuses on the preferences of tourists regarding public attributes as revealed in the room prices for hotels and second home accommodations. The paper highlights the importance of location as a source of public attributes which tourists enjoy, as public safety, beach quality, natural environment, sports facilities, heritage sites, retail stores. Furthermore, it presents the directions and guidelines for managers to develop price and promotion strategy for competitive advantage.

As the previously mentioned papers, our study is conducted from the supplier's perspective- management of the tourism establishment. The prices, settled by managers are those observed in the markets, and posted on websites or brochures. Even more, these are the expected prices to be paid by customers. Our data, prices and attributes for accommodations establishments, were gathered from the one of the most known Romanian tourism website, namely turistinfo.ro (http://www.turistinfo. $\mathrm{ro} /$ ). The rapid development of online tourism has a great impact over the tourism industry. Tourism websites facilitate communication between customers and tourism entity; the online marketing strategy dominates tourism and accommodation businesses.

\section{Romanian Tourism Market: Specific Features and Statistics}

After December 1989, the economy of Romania underwent significant changes, which were also 
reflected in tourism. In early 1990s, both tourism demand and supply experienced a significant fall. The number of accommodation units dropped from 3,213 units in 1990 to 2,905 units in 1995, as a result of difficulties in operation and a lack of legislation on tourism privatization (Rădulescu \& Stănculescu, 2012). In the following years, particularly from 2002 onwards, the tourism activity recorded an ascending trend, and 6,009 establishments are recorded in 2013. The statistics reveal a growing number of small capacity accommodation units to the detriment of large units (prevailing in early 1990s). This ascending trend is explained by the steady economic growth rate, from $2.1 \%$ in 2000 to $7.3 \%$ in 2008 (Anghelache, 2012) and by the European funds allocated to Romania for this sector, following the accession to EU in 2007. The tourism demand decreased until 2000 , remained relatively constant until the outburst of the economic and financial crisis, following which it recorded a rapid drop; the occupancy rate of the accommodation capacity was of $57.8 \%$ in $1990,35.5 \%$ in $2000,35 \%$ in 2008 , and respectively $25.1 \%$ in 2013 . The inversely proportional relation between the evolution of supply and demand is supported by Romanians' desire to develop small businesses in the hospitality industry, which was considered a source of future profits.

Our empirical study focuses on small and medium-sized accommodation units, such as guest houses, villas and houses, hostels and tourist chalets located in Romania. Such units are almost entirely privately-owned. The first private establishments emerged after 1990 as tourism and agro-tourism guest houses, and increased from 16 units in 1993 to almost 30 thousand units in 2013; the accommodation capacity of these units is currently about 56 thousand bed-places. The category of guest houses expanded heavily in particular after 1996, as a result of the initiative of numerous private entrepreneurs to start a business in tourism. As regards the different types of tourist accommodation establishments, in 2013 the rural and agro-tourism guest houses recorded $49 \%$ of the total accommodation units, hotels $24 \%$, while the rest were other collective accommodation establishments (e.g. tourist villas, bungalows, hostels, tourist chalets). The data source for the Romanian tourism statistics is the National Institute of Statistics, unless otherwise mentioned. In terms of the accommodation capacity, hotels continue to rank first.

Although following an ascending trend until 2007, as shown in Figure 1, the occupancy rate of the accommodation capacity in the case of guest houses remains relatively low, ranging between $22.3 \%$ (in 2007) and $14.6 \%$ (in 2010). In the case of agro-tourism guest houses, classified as a distinct category since 2000 , the occupancy rate ranged between $8 \%$ (in 2000) and 18.4\% (in 2008). The guest house is defined as a low-capacity establishment (up to 20 rooms and maximally 60 bed-places). The agro-touristic guest house is a smaller accommodation structure, with a capacity of up to 8 rooms, usually located in a rural environment which provides the opportunity to partake in household or craft activities. The occupancy rate trends for guest houses, touristic villas, chalets, hotels and overall are presented in Figure 1. Although the difference between the occupancy rate of hotels and that of small-size establishments like guest houses diminished in time, the latter continue to register a low occupancy rate.

As regards other types of accommodation units, Romania has preserved a significant number of units built before 1990. In 1990, the prevailing establishments were hotels (830 units), tourist villas (151), chalets (226), campings (217), school camps (203 units). Except for hotels, the other establishments decreased in number over the following years. Most of these establishments ceased their activity, mainly as a consequence of the delayed privatization process of the tourist accommodation establishments (Rădulescu \& Stănculescu, 2012).

Hotels remain the structure with the highest accommodation capacity. In 1990 a number of 830 hotels were operational, providing an accommodation capacity of 168 thousand places, and in 2013 their number increased to 1,429 units, while the accommodation capacity increased to about 182 thousand places. We can notice that investors preponderantly pursued smaller capacity hotels. The occupancy rate of the accommodation capacity decreased from $65.8 \%$ in 1990 to $31.7 \%$ in 2013 , however remaining, for the entire period, significantly higher than that of guest houses (Fig. 1). The representative of the Romanian hotel associations stated that "the low occupancy rate actually reflects the touristic attractiveness 


\section{Fig. 1: Net occupancy rates of the tourism accommodation capacity}

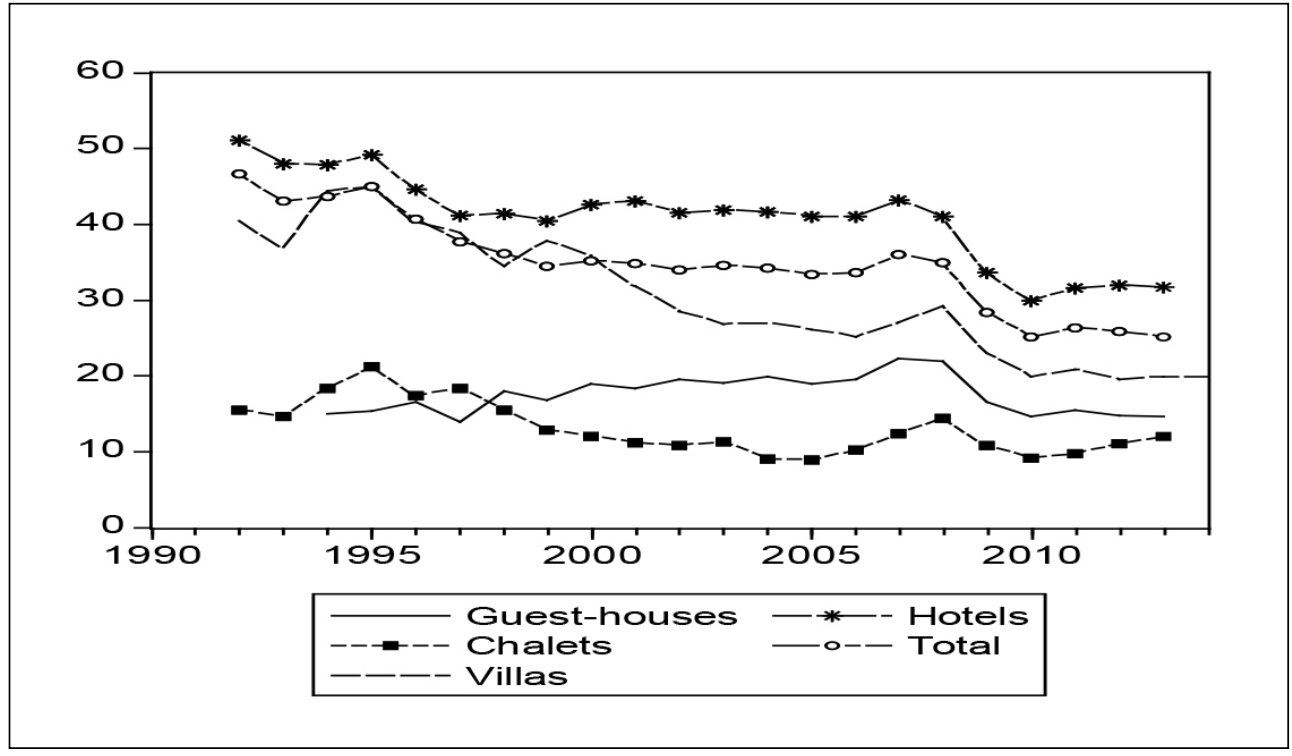

Source: own based on data from the National Institute of Statistics http://statistici.insse.ro/

of Romania. The explanations are manifold and already stereotyped, such as the transport infrastructure, the tourist areas infrastructure, the lack of efficient and consistent advertising cantered on a country brand and the lack of local advertising". An important number of hotels, respectively $84.5 \%$, were at the end of 2013 entirely privately-owned. After 1990 began a slow privatization process of the state owned hotels; the ratio of entirely privatelyowned hotels was of $25.6 \%$ in 1999.

The tourism demand registered a significant growth in the case of small and medium-sized establishments. The ratio of tourist arrivals in tourism and agro-tourism guest houses was merely of $2.4 \%$ in 2000 , as compared to $14.5 \%$ in 2013. Nevertheless, the occupancy rate still remains relatively low, and the managers/ owners of these establishments are compelled to continuously adjust their tourism products to meet the market requirements, in order to preserve old customers and to attract new ones.

Our study aims to identify the factors which influence the accommodation rates variance, information which could prove useful to the owners of small and medium-sized establishments, enabling them to adjust their prices to attract more clients, to increase the occupancy rate and consequently to make the business profitable.

\section{Hedonic Pricing Model: Data Sets and Empirical Results}

This paper conducts an empirical analysis on a sample of small and medium-sized accommodation establishments from Romania. A database referring to room rates and specific attributes was gathered from the Romanian website turistinfo.ro. We chose this particular site on the consideration that it is the most popular in the Romanians hospitality industry (according to traffic.ro). This website contains a comprehensive online database about over five thousands accommodation establishments, guest-houses, villas and houses, tourist chalets from Romania, which is regularly updated. Accommodation establishments registered in the database are mostly oriented to leisure, nature and recreational tourism and are located in the rural areas of the country. Because of the specificities of the database we mention that our study does not include business tourism 
oriented establishments; these are widely distributed in the urban area and they mostly include large and medium entities.

Data has been collected during the second half of January, 2014. The website turistinfo.ro maintains a direct contact with the accommodation units. The price shown by the website is usually the same with the final price paid by the tourist. Collected data covers 530 accommodations establishments (representing approximately $10 \%$ of the listed units), having the following structure: $59.6 \%$ guest-houses, $24.2 \%$ tourist villas and houses, $6.6 \%$ tourist chalets, $9.6 \%$ hotels. The small share for hotels is explained by the specificity of the website, in which are gathered mainly small and medium units. We mention that were selected accommodation units that had reviews made by clients, considering that these were more frequently accessed. The initial sample counted 715 accommodation establishments, but due to the lack of data on whether or not breakfast was included in the price, the location of the unit, number of stars, etc. We also excluded one star units as lacking in interest for the studio and five star units, encountered only in the case of larger hotels, which are outside the scope of this study. Eventually our sample contained 530 units, representative as regards the type of unit, type of landscape, geographical areas.

Most units are small and medium accommodation establishments. The average number of rooms per unit is of 12 rooms, with a standard deviation of 11 rooms. According to the type of landscape the distribution within the sample is: $61.7 \%$ mountain side, $20 \%$ hill side, $12.6 \%$ plane side and $5.7 \%$ sea side. In order to get a representative sample, units from all geographical areas were chosen. Percentages are between $3-8 \%$ for all regions, according to the registered number of units for each region. In respect of the stars (or flowers) rating criterion, the sample has the following structure: $25.1 \%$ units with " 2 stars", $65.8 \%$ units " 3 stars" and $9.1 \%$ units " 4 stars".

The dependent variable is one night room rate for a double room. We consider the average price of the two prices, in the case when there are different rates for the same room, depending on the week period (week-day or week-end). We mention that the mean price, in our sample, is 106.8 Lei (about 24 Euro), with a standard deviation of 36.3 Lei. The distribution of room prices is skewed to the right.

The price hedonic theory offers no guidelines in selecting a specific set of explanatory variables (Andersson, 2000). Their selection in the present context is based on the previous empirical research on this topic, and in particular on the set of relevant attributes available from the website. The attributes included in our reported hedonic pricing models are indicated in Table 1, as following: the number of rooms in the accommodation establishment, the location

Tab. 1: Description of the variables and descriptive statistics $(n=530)$

\begin{tabular}{l|l|r|r}
\multicolumn{1}{c|}{ Variable } & \multicolumn{1}{|c|}{ Description of the variable } & Mean & St. dev. \\
\hline Price & Room rate per night (lei) & 106.79 & 36.32 \\
LnPrice & Log of price & 4.61 & 0.32 \\
Rooms & Number of rooms & 12.36 & 11.57 \\
LnRooms & Log of number of rooms & 2.28 & 0.62 \\
Breakfast & Breakfast is provided (yes = 1) & 0.44 & 0.49 \\
Pet & Pets are allowed (yes = 1) & 0.35 & 0.47 \\
Bike & Bike/ATV for rent (yes = 1) & 0.11 & 0.31 \\
NearLake & Near lake (yes = 1) & 0.63 & 0.48 \\
NearAttraction & Near tourist attractions (yes =1) & 0.84 & 0.36 \\
NearThermal & Near thermal bath (yes = 1) & 0.23 & 0.42 \\
NearCity & Near town (yes = 1) & 0.59 & 0.49 \\
IsolatedPlace & Isolated place (yes = 1) & 0.21 & 0.41 \\
StarRating & Star rating: 2 stars (reference category), 3 stars, 4 stars & & \\
Type & Type of establishment: guest house (reference & \\
& category), villa and house, chalet, hotel & & \\
\hline
\end{tabular}


(near lake, near tourist attractions, near thermal baths, near city, isolated place), stars rating (4 stars, 3 stars, 2 stars), establishment type (guest house, villa and house, chalet, hotel), and other amenities.

Table 1 also presents descriptive statistics for the dependent variable - price of room / night, and for the attributes. Except for the number of rooms, number of stars and the type of establishment, the other attributes are dummy variables ( 1 indicates presence of the amenity). The mean values of the dummy variables indicate the ratio of the units where the attribute of interest is present.

As a first step, the empirical analysis is conducted in log-linear traditional model, this being the approach commonly used in the empirical research literature on hedonic pricing for tourism accommodations (Salo et al., 2014). We have estimated also, the gamma regression, respectively the Inverse Gaussian regression with log-link, applying generalized linear model framework. For our data, the results obtained from the three mentioned specifications are similar. Thus, the same attributes are indicated as having a significant marginal effect on the price. Moreover, comparing the (in-sample) performance of the three specifications, the loglinear model provides a slightly better agreement between observed and predicted prices, as the mean absolute error indicator suggests. The mean absolute error $(\mathrm{MAE})=17.64$ for log-linear model, MAE $=17.72$ for Gamma regression, and $\mathrm{MAE}=17.75$ for Inverse Gaussian regression. Therefore, we report the results provided by the log-linear model (the estimated results for the other two regressions may be provided upon request).

Focusing on the log-linear specification, three models are estimated and reported in Table 2: Model 1 for whole sample, Model 2 for the sub-sample of accommodations units providing breakfast, and Model 3 estimated for the sub-sample of units not providing breakfast. There is a significant difference between room rates when breakfast is included or not (mean price with breakfast $=132.43 \mathrm{lei}$, mean price without breakfast $=86.06$ lei; the Student $t$ test for equality of two means $=18.05$, p-value $=0.00$ ).

In order to test the statistical significance of each coefficient, the Wald test was applied, which follows asymptotically a chi-square distribution with one degree of freedom $(\mathrm{df}=1)$. The likelihood ratio (LR) test, reported on the last line from Table 2, indicate an overall goodnessof-fit of the three models, as long as the null hypothesis of jointly insignificant coefficients of explanatory variables is rejected. Reported LR test is the omnibus test, which compares the estimated model against the intercept-only model; this statistic is asymptotically chi-square distributed, and a value for LR significantly greater than zero leads to the rejection of the restriction imposed by the null hypothesis.

Turning to our empirical results from Table 2, the percentage effect, of a qualitative attribute, over the room price is given by $[(\operatorname{Exp}(\beta)-1] \cdot 100$ (as long as the other attributes are the same), taking account of the log-linear form of model. The coefficients for dummy variables have been exponentially transformed, being reported in Table 2 (denoted by $\operatorname{Exp} \beta$ ). We note from Model 1 that all included variables have significant effect on the room price. The Nagelkerke coefficient of determination, measuring the extent to which the model explains the variation in data, suggest a medium goodness-of-fit for our model R-square $=0.67$; the values of R-square lie between zero and one, and a value close to one indicates a high explanatory power of the model.

The most significant attribute when setting the room rates, is Breakfast; availability of this facility increases prices by $44.5 \%$. This is an expected result, as long as this service is included in the displayed price of the room.

For the Star rating attribute we observe, as expected, a positive association between a better rating of accommodation establishment and its room rate per night. The star rating captures a set of quality attributes, as quality of room services, sports facilities (Salo et al., 2014). The minimum rating (2-stars) is considered as the reference category. A better star ranking leads to higher prices sustained by higher quality equipments, facilities, amenities, good location, or more services. The 4-stars rating determines an increase by $38.4 \%$ in room rate, while 3 -stars by $18.1 \%$, comparatively with the room prices for 2-stars units.

Referring to the variable Accommodation type, the guest house is settled as reference category. The most significant coefficient is observed for tourist chalets; the room price for these units is higher by $12.8 \%$ than for guest houses. A higher room rate for chalets type should be sustained by some specific attributes most of them external to the establishment itself, if we consider the usual location of chalets 


\section{Marketing a obchod}

\section{Tab. 2: Summary of hedonic models (dependent variable InPrice)}

\begin{tabular}{|c|c|c|c|c|c|c|}
\hline \multirow{2}{*}{ Attribute } & \multicolumn{2}{|c|}{ Model $1(\mathrm{~N}=530)$} & \multicolumn{2}{|c|}{$\begin{array}{c}\text { Model } 2(\mathrm{~N}=237) \\
\text { Breakfast included }\end{array}$} & \multicolumn{2}{|c|}{$\begin{array}{c}\text { Model } 3(\mathrm{~N}=293) \\
\text { Breakfast not included }\end{array}$} \\
\hline & $\begin{array}{l}\text { Coeff. } \beta \\
(\operatorname{Exp} \beta)\end{array}$ & $\begin{array}{l}\text { Wald } \\
\text { test }\end{array}$ & $\begin{array}{l}\text { Coeff. } \beta \\
(\operatorname{Exp} \beta)\end{array}$ & $\begin{array}{c}\text { Wald } \\
\text { test }\end{array}$ & $\begin{array}{l}\text { Coeff. } \beta \\
(\operatorname{Exp} \beta)\end{array}$ & $\begin{array}{c}\text { Wald } \\
\text { test }\end{array}$ \\
\hline LnRooms & 0.030 & $2.737^{*}$ & -0.018 & 0.438 & 0.063 & $6.397^{* *}$ \\
\hline Bike & $\begin{array}{c}0.093 \\
(1.097)\end{array}$ & $9.833^{* * *}$ & $\begin{array}{c}0.113 \\
(1.120)\end{array}$ & $7.687^{* * *}$ & $\begin{array}{c}0.091 \\
(1.094)\end{array}$ & $4.342^{* *}$ \\
\hline Pet & $\begin{array}{l}-0.081 \\
(0.922)\end{array}$ & $17.406^{\star * *}$ & $\begin{array}{l}-0.127 \\
(0.880)\end{array}$ & $19.433^{\star * *}$ & $\begin{array}{l}-0.054 \\
(0.948)\end{array}$ & $4.060^{* *}$ \\
\hline NearLake & $\begin{array}{l}-0.045 \\
(0.956)\end{array}$ & $5.162^{\star *}$ & $\begin{array}{l}-0.061 \\
(0.941)\end{array}$ & $4.149^{* *}$ & $\begin{array}{l}-0.031 \\
(0.970)\end{array}$ & 1.347 \\
\hline NearAttraction & $\begin{array}{c}0.074 \\
(1.077)\end{array}$ & $8.063^{\star * *}$ & $\begin{array}{c}0.064 \\
(1.066)\end{array}$ & 2.116 & $\begin{array}{c}0.071 \\
(1.074)\end{array}$ & $4.753^{* *}$ \\
\hline NearThermal & $\begin{array}{l}-0.046 \\
(0.955)\end{array}$ & $4.192^{\star *}$ & $\begin{array}{l}-0.010 \\
(0.990)\end{array}$ & 0.082 & $\begin{array}{l}-0.056 \\
(0.945)\end{array}$ & $3.877^{* *}$ \\
\hline NearCity & $\begin{array}{l}-0.047 \\
(0.954)\end{array}$ & $5.845^{\star \star}$ & $\begin{array}{l}-0.069 \\
(0.933)\end{array}$ & $5.365^{\star *}$ & $\begin{array}{l}-0.033 \\
(0.967)\end{array}$ & 1.645 \\
\hline IsolatedPlace & $\begin{array}{l}-0.071 \\
(0.931)\end{array}$ & $9.341^{* * *}$ & $\begin{array}{l}-0.101 \\
(0.904)\end{array}$ & $8.305^{\star * *}$ & $\begin{array}{l}-0.055 \\
(0.947)\end{array}$ & $3.038^{*}$ \\
\hline $\begin{array}{l}\text { Type: } \\
\text { Guest house } \\
\text { Hotel }\end{array}$ & $\begin{array}{c}- \\
0.095 \\
(1.100)\end{array}$ & $\begin{array}{c}15.380^{* * *} \\
- \\
6.483^{* *}\end{array}$ & $\begin{array}{c}- \\
0.146 \\
(1.157)\end{array}$ & $\begin{array}{c}11.35^{\star * \star} \\
- \\
7.986^{\star * *}\end{array}$ & $\begin{array}{c}- \\
0.061 \\
(1.063)\end{array}$ & $\begin{array}{l}7.159^{*} \\
- \\
1.181\end{array}$ \\
\hline Chalet & $\begin{array}{c}0.121 \\
(1.128)\end{array}$ & $9.875^{* * *}$ & $\begin{array}{c}0.116 \\
(1.123)\end{array}$ & $4.008^{* *}$ & $\begin{array}{c}0.125 \\
(1.133)\end{array}$ & $6.031^{* *}$ \\
\hline VillaOrHouse & $\begin{array}{c}0.018 \\
(1.018) \\
\end{array}$ & 0.608 & $\begin{array}{c}0.008 \\
(1.008) \\
\end{array}$ & 0.034 & $\begin{array}{c}0.028 \\
(1.028) \\
\end{array}$ & 0.906 \\
\hline $\begin{array}{l}\text { StarRating: } \\
2 \text { stars }\end{array}$ & - & $\begin{array}{l}89.25^{* * *} \\
-\end{array}$ & - & $\begin{array}{c}28.97^{* * *} \\
-\end{array}$ & - & $\begin{array}{l}57.62^{* \star *} \\
-\end{array}$ \\
\hline 3 stars & $\begin{array}{c}0.166 \\
(1.181)\end{array}$ & $53.680^{* * *}$ & $\begin{array}{c}0.136 \\
(1.146)\end{array}$ & $10.931^{* * *}$ & $\begin{array}{c}0.171 \\
(1.189)\end{array}$ & $41.406^{* * *}$ \\
\hline 4 stars & $\begin{array}{c}0.325 \\
(1.384) \\
\end{array}$ & $76.732^{* * *}$ & $\begin{array}{c}0.285 \\
(1.329) \\
\end{array}$ & $28.930^{* * *}$ & $\begin{array}{c}0.360 \\
(1.413) \\
\end{array}$ & $35.764^{* * *}$ \\
\hline Breakfast & $\begin{array}{c}0.368 \\
(1.445)\end{array}$ & $348.63^{\star * *}$ & - & - & - & - \\
\hline Intercept & $\begin{array}{c}4.261 \\
(70.388)\end{array}$ & $6,881 \cdot 3^{* * *}$ & $\begin{array}{l}4.734 \\
(123.8)\end{array}$ & $2,987.0^{\star * *}$ & $\begin{array}{c}4.160 \\
(64.051)\end{array}$ & $3,904.1^{* * *}$ \\
\hline LR test & \multicolumn{2}{|c|}{$459.77^{* * *}(\mathrm{df}=14)$} & \multicolumn{2}{|c|}{$74.65^{\star \star \star}(\mathrm{df}=13)$} & \multicolumn{2}{|c|}{$97.95^{\star \star *}(\mathrm{df}=13)$} \\
\hline
\end{tabular}

Source: own

Note: ${ }^{*}$ denote significance at $10 \%,{ }^{* *}$ significance at $5 \%,{ }^{* * *}$ significance at $1 \%$.

(mountain area, places with low touristic density or isolated places). The rooms from hotels are more expensive by $10 \%$ than those from guest houses. There are no significant differences between the room price for villas or houses, and the room price for guest houses.

The attractive neighbourhoods of accommodation establishment have a significant role 
in the pricing policy. Similar empirical results have been obtained by Salo et al. (2014), Rigall-I-Torrent and Fluvia (2011), among others. If we consider the attribute Near tourist attractions, the empirical results suggest that there is an opportunity for higher prices supported by attractive neighbourhoods. Thus, an accommodation unit located near a tourist attraction can set, on average, a room price higher by $7.7 \%$ (other attributes being identical). Taking advantage of this attribute does not always imply a direct cost for the accommodation unit, if we assume that local communities and other private companies are involved into attracting the visitors.

All the other three attributes (near lake, near thermal baths, near city) seem to be unattractive from the price formation point of view. The coefficients associated with these attributes are borderline significant, therefore they should be interpreted with caution; at $1 \%$ significance level, these attributes have no effect on the price. For Isolated place the coefficient is significant and negative, showing that the price settled by these accommodation units is lower than for the rest of units. In other words, there is no reason to increase room rates when this attribute is present. Possible explanation could be related to external factors, as public facilities or infrastructure which do not sustain the tourism development in these areas. We also mention that during the last years increased the investments coming from European funds, especially in small and medium accommodation units, strongly contributing to increased competition.

The Bicycle/ATV rent facility has a positive effect on the price, while Pets allowed gives no reason for increasing the price. The room price at accommodation units with sports facilities is, on average, $9.7 \%$ higher. Sports facilities are positively evaluated also by other studies (Pompurová \& Šimočková, 2014; Rigall-I-Torrent \& Fluvia, 2011). While the first characteristic is considered a healthy habit, a sport, the latter suggests that pets are not a good reason for charging higher rates. If the first attribute attracts clients, the other seems to act in an opposite way because of the low level of tolerance coming from non-pets allowed clients; the pets are allowed usually in low rated units.

The Number of rooms has a borderline, positive effect. An increase of accommodation unit capacity seems to be associated with higher prices. For these units, there are more opportunities to develop complementary services, to be delivered with the basic accommodation one. Even more, when comparing the average prices for each type of accommodation we conclude that hotels have both more rooms and higher prices, in our sample of establishments.

On the other hand, we briefly explore the effects of attributes on room rates, for the subsample of accommodations units providing a breakfast (Model 2, breakfast included), and for the units not providing breakfast (Model 3, breakfast not included). Part of the empirical results is similar with those from Model 1, but some specific issues can be also seen.

Related to the Model 2, the Star rating, and the facility of Bicycle/ATV for rent, we can still observe a positive and significant effect on the room rate. For these units, that include breakfast like a mandatory service, the hotel rooms are more expensive, the rate being by $15.7 \%$ higher than for guest houses. The number of rooms, location near a tourist attraction and location near thermal baths become clearly insignificant in explaining the room price variability. There is no willingness to pay a marginal price for a location near a tourist attraction.

In the case of accommodation units with no breakfast included (Model 3), the type of accommodation has no significant impact on the room price, at conventional $5 \%$ significant level; there is still a weak association, significant at $10 \%$ significance level (the joint Wald test $=7.16 ;$-value $=0.067)$. Therefore, there are small differences between prices of the rooms for the considered types of accommodation. The number of stars remains clearly a significant determinant of room rates; the 3-stars and 4-stars accommodation units have a price significantly higher than 2-stars units, by $18.9 \%$ and $41.3 \%$ respectively. There are more variables with positive, but borderline significant influence on the room price: Bicycle/ATV for rent, number of rooms, near a tourist attraction. Presence of the attributes: allowing pets, near thermal bath and isolated place seems to be associated to lower priced rooms, but these results should be viewed with caution, taking into account that the coefficient of these variables becomes insignificant at $1 \%$ significance level. The attributes Near lake and Near city have no significant effect on the room 
price; they don't contribute either to an increase or a decrease in room rates.

\section{Conclusions and Findings for Managers and Public Organizations}

A flexible pricing strategy could become an effective and efficient tool for tourism entities in order to increase their performance. On a dynamic market, the price formation policy has become a real strategic issue for the entrepreneurs from tourism sector. The hedonic pricing model makes possible to highlight the attributes that have a significant contribution to the price, and help to quantify the contribution of each of them. This analysis suggests which attributes are valued by consumers and to what extent (Falk, 2008).

This paper contributes to the empirical tourism literature by highlighting and applying the hedonic pricing model, in order to investigate the significance of accommodation attributes in the formation of room rates. Useful information for entrepreneurs from tourism can be obtained. The dependent variable, in our study is one night room rate for a double room. The data has been collected from the website turistinfo.ro, and covers small and medium accommodation establishments, most of them from the rural area. We consider this aspect a favorable one because it enabled us to get information about these units, which are more and more representative for the Romanian tourism market, according to the statistics.

In the empirical section are estimated and reported the following log-linear regressions: Model 1 for whole sample, Model 2 for the subsample of accommodations units providing a breakfast meal, and Model 3 estimated for the sub-sample of units not providing breakfast. There are some attributes with significant effect on the room price for all three models, but with different intensity: star rating, accommodation type, pets allowed, bicycle/ATV rental. The most important empirical findings from the perspective of the attributes' contribution to the price are the following:

- Star rating, which actually captures the quality attributes, has the highest effect on the price;

- The type of accommodation has a different importance, according to the model;

- Bicycle/ATV rental, as a proxy variable for sports facilities, has a positive contribution to price increase;
- There is no empirical support for allowing pets, and location in isolated place in order to increase the price;

- Some models suggest that there is an opportunity for higher prices supported by attractive neighbourhood, e.g. the tourist attractions near the location;

- Related to the breakfast, availability of this service increases prices by $44.5 \%$.

Tourism managers can use the information provided by hedonic analysis to price products and design effective marketing strategies (Chen \& Rothschild, 2010). Papatheodorou et al. (2012) emphasize the importance of hedonic model in tourism industry for different beneficiaries - entrepreneurs and managers, from both private and public entities involved in the tourism sector.

The findings from this paper could be used for pricing policies by managers or marketers. They may use the information in the decision making process regarding the price, and can develop marketing strategies based on price, allowing them to attract loyal customers, ultimately. The managers have to pay more attention to their internal facilities, goods or amenities and to be committed to increasing the quality of their service delivery process; for example, the sports facilities, as bicycle/ATV rental, could contribute to price increase. Even more, these characteristics which contribute to price increase can also determine a differentiated offer compared with other establishments, and finally to increase the customer satisfaction, and to attract new segments of customers (Espinet, Saez, Coenders, \& Fluvià, 2003).

The results of this study are valuable for the future investors in tourism, as they are for actual entrepreneurs. Even though their role is similar with the managers' one in many cases, we could add that they can get information about what part of the business to be developed and in what direction, quantitative or qualitative. Thus, they will have good opportunities to complete the offer in order to charge a higher price to the customers. For the start-up businesses they can develop a structured offer, including the required attributes which to enable them to move more quickly through the initial stages of the business, usually characterized by lower efficiency levels.

A third beneficiary of the hedonic analysis in tourism are public organizations and local administration. These organizations can 
develop appropriate policies for regional development, focusing on those characteristics with high significance in price formation, as the hedonic pricing models suggest. Even though public organizations do not benefit in a direct way, they will contribute to the area development and to some other business developments as well. All these aspects will generate revenues and opportunities for a sustainable development of tourism and of the geographical region.

As already mentioned, price is a useful tool available to managers to increase revenues from accommodations. Thus, it is important to analyse all the factors which contribute to price setting in order to determine their best combination. In the service sectors, which include tourism, it is important to set the right price due to a higher customer sensitivity compared to other sectors. Whether we consider quantitative or qualitative factors, they all contribute to a higher quality of the service delivery. The right price contributes to a better ratio between the quality of the service and its price, which enables higher performance, a better market share or notoriety.

We should mention that, due to certain particularities of the Romanian tourism, the role of pricing strategies is even more important:

- As shown by the statistical data, the market has a considerable growth potential for the category of small and medium entities.

- It is known worldwide that in tourism, more than in other sectors, external factors play a crucial role for the service delivery, as well as for price setting. In Romania, the external factors - environment, surroundings and infrastructure - are less developed and therefore bear a higher potential to trigger higher prices if they are improved.

- The periods of decline - financial crisis are more sensitive for the Romanian tourism industry because of the average customer profile, characterised by lower purchasing power, income level and standard of living.

The validity of the research is given by the three models selected which reflect the Romanian specific environment of the tourism industry, in the area of small and medium accommodation units. Also, the determined sample of tourism establishments ensures the representativeness of the data and provides valuable results for price setting to entrepreneurs and managers of small and medium units.
Within a comprehensive approach, the paper recommends managers and entrepreneurs to put in place the following measures, from the perspective of the pricing strategy applied on the Romanian tourism market:

- To develop and sustain accommodation units with breakfast included;

- To focus on medium size tourism establishments, rated 3-4 stars;

- To develop additional services which contribute to higher prices - Bicycle/ATV rental;

- To choose locations for future entities nearby tourist attractions- Near Attraction;

- To put less emphasis on other services which don't actually contribute to higher prices - Pet Allowed or Near Lake, Thermal or City.

All the previous suggestions lead to a better quality-price ratio of the tourism service. Thus, the financial results could contribute to better performance.

From the perspective of local and regional development there is a need of efficient communication between the tourism managers and entrepreneurs on one hand and the public organizations on the other, in order to enhance infrastructure development. Thus, factors which according with our study don't have a positive impact on pricing strategy could become significantly important for the future.

There are some limitations of this study, highlighting further directions for research. Our sample mostly includes establishments from rural area, of small-medium size. Thus, an extension of the study could be conducted by analyzing other accommodation types, like hotels from urban areas or hotels located by the beach. The main goal of the paper was to highlight attributes with a positive influence in price increase, in order to improve the financial indicators of the tourism establishment - its efficiency. It seems to be in contradiction with the trend of decreasing prices, as long as the current tourism market is characterized by more intense competition. Within this context, future studies are useful, due to the dynamic of the external environment, in order to design an appropriate offer for each segment of customers, and to increase their satisfaction. This study was conducted from the perspective of the accommodation establishment. An increased attention should be given to find out how the strategies and policies developed by different 
stakeholders are perceived by the ultimate beneficiary of the touristic product - the tourist.

\section{References}

Abrate, G., Fraquelli, G., \& Viglia, G. (2012). Dynamic pricing strategies: Evidence from European hotels. International Journal of Hospitality Management, 31(1), 160-168. doi:10.1016/j.ijhm.2011.06.003.

Andersson, D. E. (2000). Hypothesis testing in hedonic price estimation - on the selection of independent variables. Annals of Regional Science, 34(2), 293-304. doi:10.1007/s001689900010.

Bull, I., Thomas, H., \& Willard, G. (1995). Entrepreneurship: Perspectives on Theory Building. New York: Pergamon.

Anghelache, C., Anghelache, V. G., \& Anghel, M. G. (2012). Evolutia Produsului Intern Brut. Investitii straine directe in ultimul deceniu. Revista Romana de Statistica Trim I-Supliment, 198-204. Retrived from http://www.revistadestatistica.ro/ suplimente/2012/1/srrs1_2012a35.pdf.

Cassidy, K., \& Guilding, C. (2007). Tourist accommodation price setting in Australian strata titled properties. International Journal of Hospitality Management, 26(2), 277-292. doi:10.1016/j.ijhm.2006.10.005.

Chen, C. F., \& Rothschild, R. (2010). An application of hedonic pricing analysis to the case of hotel rooms in Taipei. Tourism Economics, 16(3), 685-694. doi:10.5367/000000010792278310.

Collins, M., \& Parsa, H. G. (2006). Pricing strategies to maximize revenues in the lodging industry. International Journal of Hospitality Management, 25(1), 91-107. doi:10.1016/j. ijhm.2004.12.009.

Ekeland, I., Heckman, J. J., \& Nesheim, L. (2004). Identification and estimation of hedonic models. Journal of Political Economy, 112(1), 60-109. doi:10.1086/379947.

Espinet, J. M., Saez, M., Coenders, G., \& Fluvià, M. (2003). Effect on prices of the attributes of holiday hotels: a hedonic prices approach. Tourism Economics, 9(2), 165-178. doi:10.5367/000000003101298330.

Dwyer, L., Forsyth, P., \& Dwyer, W. (2010). Tourism Economics and Policy. Cheltenham, UK: Channel View Publications.

Falk, M. (2008). A hedonic price model for ski lift tickets. Tourism Management, 29(6), 11721184. doi:10.1016/j.tourman.2008.02.021.

Hamel, G. (2007). The Future of Management. Boston: Harvard Business Publishing.
Hung, W. T., Shang, J. K., \& Wang, F. C. (2010). Pricing determinants in the hotel industry: Quantile regression analysis. International Journal of Hospitality Management, 29(3), 378384. doi:10.1016/j.ijhm.2009.09.001.

Kotler, P., \& Keller, K. L. (2011). Marketing Management (14th ed.). New Jersey: Prentice-Hall.

Mcculloch, C. E., \& Searle, S. R. (2008). Generalized, linear, and mixed models. New York: John Wiley and Sons.

Papatheodorou, A., Lei, Z., \& Apostolakis, A. (2012). Hedonic Price Analysis. In L. Dwyer, A. Gill, \& N. Seetaram (Eds.), Handbook of Research Methods in Tourism: Quantitative and Qualitative Approaches (pp. 170-182). Cheltenham: Edward Elgar Publishing Ltd.

Pompurová, K., \& Šimočková, I. (2014). Destination attractiveness of Slovakia: perspectives of demand from major tourism source markets. E\&M Ekonomie a Management, 17(3), 62-73. doi:10.15240/ tul/001/2014-3-006.

Rigall-I-Torrent, R., \& Fluvià, M. (2011). Managing tourism products and destinations embedding public goods components: A hedonic approach. Tourism Management, 32(2), 244255. doi:10.1016/j.tourman.2009.12.009.

Rădulescu, D. C., \& Stănculescu, M. S. (2012). Oferta turistică din România: 1948-2010. Calitatea Vieţii (Quality of Life), 23(4), 299-326. Retrived from http://www.revistacalitateavietii. ro/2012/CV-4-2012/02.pdf.

Rosen, S. (1974). Hedonic prices and implicit markets: Product differentiation in pure competition. The Journal of Political Economy, 82(1), 34-55. doi:10.1086/260169.

Salo, A., Garriga, A., Rigall-I-Torrent, R., Vila, M., \& Fluvià, M. (2014). Do implicit prices for hotels and second homes show differences in tourists' valuation for public attributes for each type of accommodation facility? International Journal of Hospitality Management, 36(January), 120-129. doi:10.1016/j.jjhm.2013.08.011.

World Travel \& Tourism Council (WTTC). (2014). Travel \& Tourism Economic Impact 2014 Romania. Retrived November 22, 2014, from http://www.wttc.org/-/media/files/reports/ economic\%20impact\%20research/country\%20 reports/romania2014.pdf.

Zhang, H., Zhang, J., Lu, S., Cheng, S., \& Zhang, J. (2011). Modeling hotel room price with geographically weighted regression. International Journal of Hospitality Management, 30(4), 1036-1043. doi:10.1016/j.jphm.2011.03.010. 
Assoc. Prof. Anuţa Buiga, Ph.D. Babeş-Bolyai University of Cluj-Napoca Faculty of Economics and Business Administration Department of Statistics, Forecasting, Mathematics anuta.buiga@econ.ubbcluj.ro

Assoc. Prof. Roxana Stegerean, Ph.D. Babeş-Bolyai University of Cluj-Napoca Faculty of Economics and Business Administration Department of Management roxana.stegerean@econ.ubbcluj.ro
Assoc. Prof. Alexandru Chiş, Ph.D. Babeş-Bolyai University of Cluj-Napoca

Faculty of Economics and Business Administration

Department of Marketing alexandru.chis@econ.ubbcluj.ro

Prof. Dorina Lazăr, Ph.D. Babeş-Bolyai University of Cluj-Napoca Faculty of Economics and Business Administration Department of Statistics, Forecasting, Mathematics dorina.lazar@econ.ubbcluj.ro 


\title{
Abstract
}

\section{PRICING OF THE TOURISM PRODUCT: A TOOL FOR ENTREPRENEURS TO ADAPTTO A FLEXIBLE MARKET}

\author{
Anuța Buiga, Roxana Stegerean, Alexandru Chiş, Dorina Lazăr
}

The paper approaches the hedonic pricing analysis as a useful instrument for tourism entrepreneurs to get a competitive advantage through price setting policies. The main goal of this research is to conduct an analysis useful to measure the marginal effect of the attributes which contributes to price setting; the empirical analysis is developed on the prices of accommodation establishments from Romania. The study focuses on small and medium sized accommodation units, most of them entirely privately-owned. Within the analysis we set attributes from inside and outside the accommodation establishment as long as they are both ultimately linked with the pricing policy. Several hedonic specifications are estimated, in order to investigate the significance of accommodation attributes in the formation of room rates. There is a set of attributes with significant effect on the room price in all models, but with different intensity. The managers have to pay more attention to their internal facilities, goods or amenities (as recreational facilities), and to be committed to increasing the quality of their service delivery process, but there is also an opportunity for higher prices supported by attractive neighbourhoods. These findings are useful for the entrepreneurs interested in developing new businesses in tourism but also for managers already performing in the sector. Both categories have to face challenges such as new services development, price setting policy, choosing new locations. A flexible pricing strategy could become an effective and efficient tool for accommodation units in order to increase their performance. These elements are potential competitive dimensions and provide good opportunities for adapting to a dynamic market. Public and local administration organizations can develop appropriate policies for regional development based on hedonic models and thus, generate revenues and create opportunities for a sustainable development of tourism and also of the geographical region.

Key Words: Tourism entrepreneurship, pricing strategy, hedonic pricing model, attributes for price setting.

JEL Classification: L83, L26, L11, C20.

DOI: 10.15240/tul/001/2017-1-012 